\title{
Transnasal endoscopic eustachian tube balloon dilation: a review
}

\author{
Santosh Kumar Swain*, Alok Das, Satyabrata Acharya, Jatindra Nath Mohanty
}

Department of Otorhinolaryngology, IMS and SUM Hospital, Siksha “O” Anusandhan University, Bhubaneswar, Odisha, India

Received: 12 September 2019

Accepted: 08 November 2019

\section{*Correspondence:}

Dr. Santosh Kumar Swain,

E-mail: santoshvoltaire@yahoo.co.in

Copyright: $($ the author(s), publisher and licensee Medip Academy. This is an open-access article distributed under the terms of the Creative Commons Attribution Non-Commercial License, which permits unrestricted non-commercial use, distribution, and reproduction in any medium, provided the original work is properly cited.

\begin{abstract}
Eustachian tube (ET) dysfunction is a common clinical entity which often provides challenges to Otorhinolaryngologists. Patients with ET dysfunction typically present with fullness in the ear, hearing loss or plugging in the ear, which impair quality of the life. It can lead to cholesteatoma formation and severe morbidity in the life. There are limited treatment options for ET dysfunction in clinical practice. Presently transnasal endoscopic balloon dilation of ET is a promising treatment for its dysfunction. This technique causes inflation of a balloon in the cartilaginous portion of the ET which leads to local dilation. This procedure helps in reduction of the clinical symptoms and reduces the severity of the ET dysfunction such as hearing loss and cholesteatoma formation. This review article will discuss the effectiveness of transnasal endoscopic balloon dilatation of eustachian tube for treatment of chronic eustachian tube dysfunction.
\end{abstract}

Keywords: Transnasal, Endoscopic, Eustachian tube, Balloon dilation

\section{INTRODUCTION}

Eustachian tube (ET) dysfunction is a common clinical entity, found in at least $1 \%$ of the adult. ${ }^{1}$ ET dysfunction can cause impaired quality of life because of feeling of fullness in the ear, otalgia and intolerance to air travel or scuba diving. It can also lead to hearing loss and formation of cholesteatoma. ET dysfunction is a common problem among children and often persists in adulthood. ET dysfunction to hearing loss affects the patients in daily activity. Feeling of blocking in the ear or slight hearing loss provides discomfort independent of the etiologies of these disorders. The etiology for ET dysfunction are allergy, infections, laryngopharyngeal reflux, primary mucosal disease, defective dilatational mechanism and anatomical obstruction of the eustachian tube. $^{2,3}$ ET dysfunction can lead to different otological manifestations such as serous otitis media and chronic otitis media. ${ }^{4}$ The treatment of ET dysfunction is often difficult and the dilation of the lumen of ET provides modest improvement functions of the ET and improves tympanogram. Recently transnasal balloon dilation of the ET is emerged as a useful technique in the treatment of the eustachian tube dysfunction. This review article reviews details of this current novel treatment such as transnasal endoscopic balloon dilation of eustachian tube in chronic eustachian tube dysfunctions including its history, anatomical and physiological considerations, indications, pre-operative evaluation, surgical technique, drawbacks and complications of this technique.

\section{METHODS}

For searching the published article, an electronic search of the SCOPUS, Medline and PubMed databases was conducted. The search term in the database included eustachian tube, balloon dilation and endoscopic approach. The abstracts of the published articles are collected by this search method and other articles were identified manually from the citations. This review article reviews transnasal endoscopic balloon dilation of eustachian tube. This review article discusses about 
history, anatomical and physiological consideration, indications, pre-operative evaluation, surgical technique, drawbacks of this technique and complications of this procedure. This review article will act as spur for further studies in the endoscopic balloon dilation of eustachian tube and helps to innovate new technique for eustachian tube dysfunction.

\section{HISTORY}

Eustachian tube has been an uncommon structure with an unusual anatomical location for intervention due to its unique anatomical site, uncertain functioning of the ET and anecdotal reporting of the catastrophic complications like rupture of internal carotid artery following inadvertent Teflon injection. ${ }^{5}$ Introduction of the minimally invasive interventions in different medical fields such as urological, gastrointestinal, Otolaryngological and cardiac sciences solving several medical illness. Use of micro-catheter and endoscopes improves the operative techniques like eustachian tuboplasty with stenting materials, eustachian tuboplasty with laser or eustachian tuboplasty with microdebrider. ${ }^{6,7}$ The development of transnasal endoscopic surgery along with inflatable balloons in cardiac sciences and presently in sinonasal surgery has opened up a new era for treating the ET dysfunction. The new technique for endoscopy of ET was done by Yamashita with the help of flexible fiberscope and an instrument channel for insufflations of air to expand the lumen of the ET. ${ }^{8}$

There is new development of miniature flexible fiberoptic systems to perform endoscopy of the ET and tympanic cavity without doing any trauma by Hopf and team. ${ }^{9}$ The special actively steerable micro-catheters, flexible fiberscope with outer diameter of 350 to $650 \mu \mathrm{m}$ are entered via nasopharyngeal opening of the eustachian tube and advanced towards the middle ear under direct visual control. However, this study was not meant to manage the ET dysfunction. ${ }^{10}$ Ockerman et al described balloon dilation of the eustachian tube as a new technique for treating patients with eustachian tube dysfunction. ${ }^{11,12}$ They used the technique of tubomanometry for assessing the eustachian tube and compared pre-operative and postoperative outcomes. There are few other techniques like sonotubometry with perfect sequences (PSEQ) were described in to find out the eustachian tube status. ${ }^{13}$

PSEQ appears promising but require validation. Transnasal endoscopic balloon dilation is a new technique in the treatment option for ET dysfunction. Conventional treatment for improving the ET dysfunction include nasal steroids, antihistamines and decongestant are used since long but unfortunately not effective in the management of this clinical entity. ${ }^{14}$ There is a popular invasive procedure like paracentesis and placement of grommet to equalize the middle ear pressure to the outside ,used to treat ET dysfunction. ${ }^{15}$ But placement of tympanostomy tube can damage the tympanic membrane and result in persistent perforation, infection of the middle ear and extrude. Laser or Microdebrider tuboplasty is used to strip the hypertrophic mucosa and cartilage at the posterior cushion of the ET and clear the obstruction. But this technique is often associated with peritubal adhesions, epistaxis and patulous ET tube. ${ }^{16}$ Till now there is no gold standard treatment for ET dysfunction. ${ }^{17}$ Presently the development of minimally invasive technique such as transnasal balloon dilation of ET is emerged as a very good technique for the management of ET dysfunction. Dr. Dennis Poe in Boston who first described this technique in 2011 and concluded that dilation of cartilaginous part of the ET found to be beneficial and without any significant adverse effects in the treatment of patient with chronic ET dysfunctions. ${ }^{11}$

\section{ANATOMICAL AND PHYSIOLOGICAL CONSI- DERATIONS}

The eustachian tube (ET) is a challenging part of the body for intervention because of its anatomical site, uncertain function and anecdotal reports for catastrophic situations like rupture of internal carotid artery following inadvertent injection of Teflon. ${ }^{18}$ The ET tube is situated at a complex site of the head and neck region so difficult to handle by an experienced hand. ET is approximately $37.5 \mathrm{~mm}$ long in adults and has bony and cartilaginous parts which extends from anterior wall of the middle ear to the nasopharynx. ${ }^{19}$ It has different physiological functions such as pressure equalization, drainage of the tympanic cavity and preventation of the reflux from the nasopharyngeal secretions or infections. ${ }^{19}$ It provide ventilation to the middle ear and so equalize the pressure of the middle ear and ambient pressure.

ET dysfunction can occur due to several diseases which interfere with the mucosal function or cartilaginous part of the tube. The exact pathophysiology is not yet elucidated in the literature and no standard test is available to objectify the dysfunction of the ET. ${ }^{17}$ Development of negative pressure in the middle ear occur due to obstructive pathology in the nasopharynx like adenoid hypertrophy or malignancy or microbial overload. $^{20}$ The cartilaginous part of the ET is often the site of pathology in ET dysfunction. ${ }^{21}$ So nasal endoscopy is very useful to assess the nasopharyngeal opening of the ET introduces the balloon catheter. This technique is an invasive surgical procedure causing temporary inflation of the balloon catheter at the cartilaginous portion of the ET.

The mechanism for balloon dilation of ET is still an ongoing research. The mechanism for dilation of ET is thought to include both anatomical widening of the cartilaginous part of ET and initiation of the histological changes. $^{22}$ One study reported that histopathological changes due to eustachian tube dilation seen that balloon had a crushing effect on inflammatory cells in the lining of the ET lumen while sparing the basal layer and 
speedily replacing the inflamed mucosa with a new fibrous scar. ${ }^{22}$

\section{INDICATIONS}

The dysfunction of ET is often called as 'Black box' where the function of the system remains unclear. Now it is increasingly clear that there is a spectrum of etiopathology leading to dysfunctions of the ET which need exact identification and its treatment. ${ }^{23}$ The function of the ET is an important prognostic factor for successful tympanoplasty. The indications for transnasal endoscopic balloon dilatation of ET are chronic ET dysfunction leading to tympanic membrane atelectasis or recurrent middle ear effusion. It is done in case of failure of tympanostomy in recurrent middle ear effusion with ET dysfunction.

This procedure can be done in case of recurrent episodes of ear discomfort with changes in altitude e.g. on an airplane flight or during diving. Presently, balloon dilation of the ET is done for treating chronic symptoms due to ET dysfunction. Poor ET dysfunction can be temporary and often spontaneously resolving. ${ }^{24}$ Chronic ET dysfunction is seen when the dysfunction lasts for more than 3 months which is poorly defined clinical entity in medical literature. Before performing the procedure, diagnosis is confirmed by different clinical examinations and investigations which includes clinical history, Otoscopy and tympanometry. ${ }^{25}$ Recently transnasal endoscopic balloon dilation is emerged as a useful technique or procedure for the management of ET dysfunction. The aim of the balloon dilation of the eustachian tube is to widen the cartilaginous part of the ET and improves its function. The site of the pathology is often at the cartilaginous part of the ET and not in the osseous portion.

\section{PRE-OPERATIVE EVALUATION}

The ET balloon dilation is not advised for pediatric patients although the reasons are difficult to understand. There is a major concern for serious complications such as chance of injury of internal carotid artery, particularly when the artery follows an anomalous course at the bony part of the eustachian tube or presence of dehiscence of the bony carotid canal. Although such concerns are present when doing balloon dilation of ET in adult patients but it is more in children where the vessel walls are thinner. This argument is appropriate if the bony part of the ET is dilated as few authors falsely believed in the past.

However, the cartilaginous part but not bony part is dilated which is present at a safe distance from the internal carotid canal. This is why, CT scan is not necessarily advised in all cases before surgery. ${ }^{26}$ Some authors argue that balloon length $(20 \mathrm{~mm})$ available in the market is unsuitable for children due to its anatomical cause. The length of the ET increases during childhood and attends its adult size at the age of 7 years. Although the length of the ET in infant is shorter than adult, the ratio of the cartilaginous part to bony part of the ET is $8: 1$ in infants in comparisons to $4: 1$ of the adults. So, the length of the balloon is not a critical factor for keeping it in bony portion of ET. However, the length of the catheters with balloon is $1.5 \mathrm{~cm}$ or $1.0 \mathrm{~cm}$ are now available in market.

Tympanometry is usually performed pre-operatively for diagnosis of eustachian tube dysfunction. ${ }^{27}$ Before performing balloon dilation of ET, details of subjective, physical and Otorhinolaryngological examinations are done in the patients. The clinical symptoms of the poor ET dysfunction are documented like feeling of obstruction or clicking noises, which are reversible or not after performing swallowing, yawning or Valsalva maneuver. Diagnostic nasal endoscopic examination of the nose and nasopharynx are done to rule out any obstructive pathology of ET opening at the nasopharynx. Both ears are examined by microscopes or otoendoscopes.

\section{SURGICAL TECHNIQUE}

This procedure is usually done under general anesthesia with topical application of nasal decongestants into nasal cavity and nasopharynx. ${ }^{28}$ This procedure is performed after subjective, physical and Otorhinolaryngological examinations. A specially designed $500 \mu \mathrm{m}$ diameter balloon catheter (Spiggle and Theis Company, Overath, Germany) (Figure 1) is introduced into the eustachian tube for a length of $20 \mathrm{~mm}$ via a special insertion instrument under guidance of rigid nasal endoscope. The catheter is inserted into nasopharyngeal orifice of the ET in the first instance (Figure 2). The balloon is inflated by sterile water with a pressure of ten bars for two minutes by help of pressure device or inflation pump (Figure 3). The inflated balloon dilates the cartilaginous part of the ET (Figure 4).

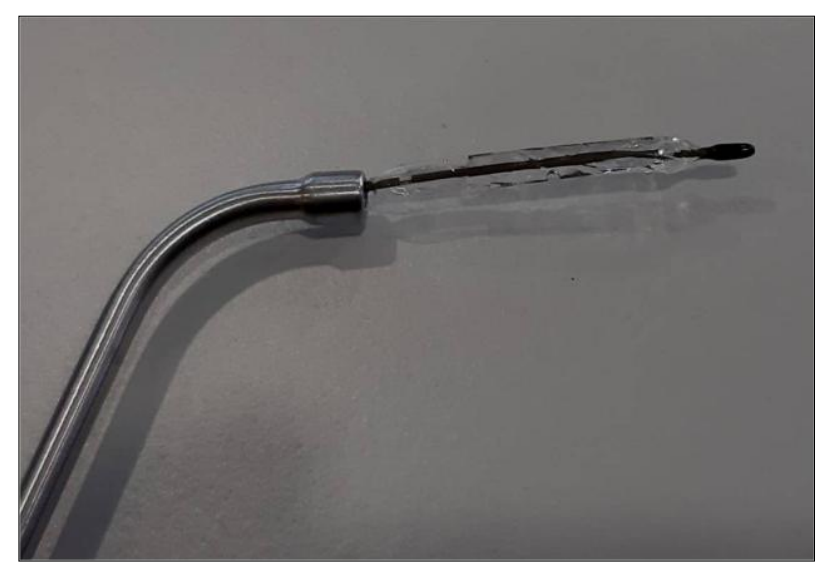

Figure 1: Balloon catheter for ET dilation.

The balloon is emptied and removed. The aim of this surgical procedure is to dilate the cartilaginous part of the 
eustachian tube without any structural damage. This is a day care procedure where patient admitted in the morning and discharged in afternoon. The day after procedure, patients are advised to do Valsalva maneuver three times a day for two weeks. Two nasal sprays may be used after the procedure like nasal decongestants for 7days and corticosteroids for 2 weeks. After 2 months of procedure, the patients are reviewed for audiological tests again. All the patients are asked questionnaire after two months of procedure on the basis of overall improvement of symptoms with the procedure. Nasopharyngeal opening of the ET is also assessed after 2 months of surgery to find out its patency .Balloon dilation of ET is a less invasive procedure in comparison to other techniques like laser or microdebrider tuboplasty. ${ }^{29}$ It is found to be safe and easy to inflate the ET and improve the ET function.

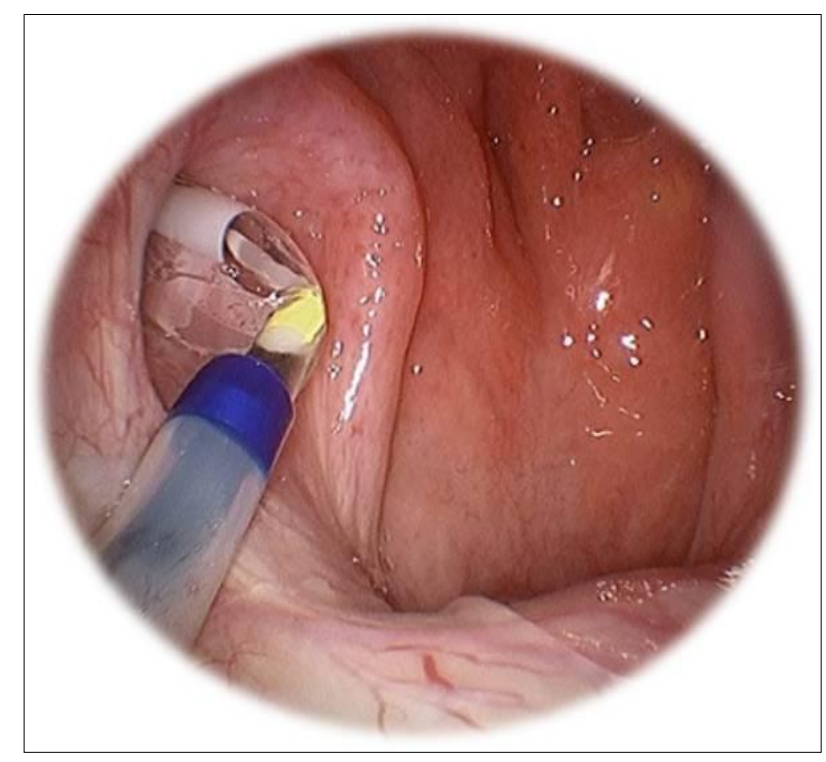

Figure 2: Balloon catheter is pushed into the cartilaginous part of the ET.

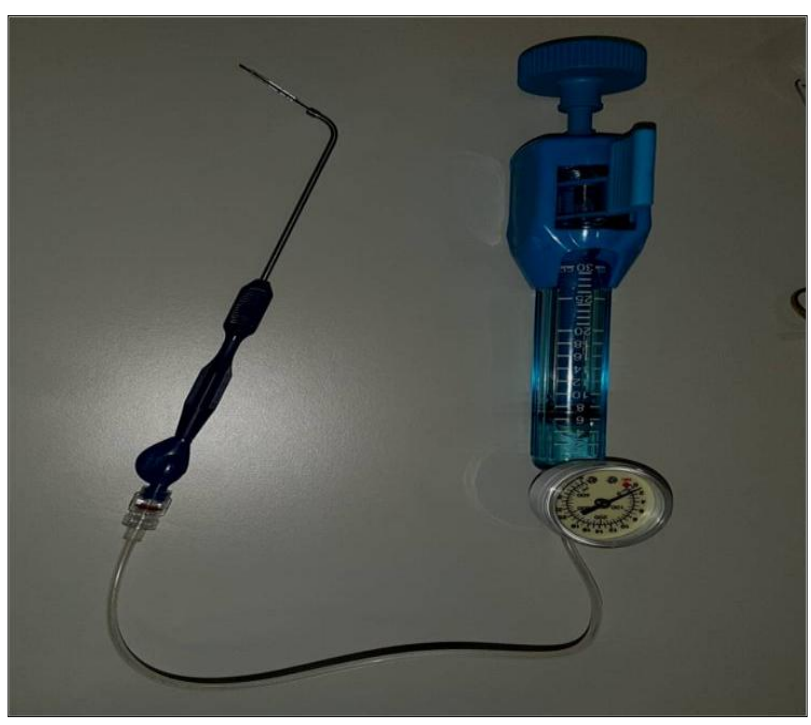

Figure 3: Pressure device (inflation pump) which is attached to the balloon catheter.

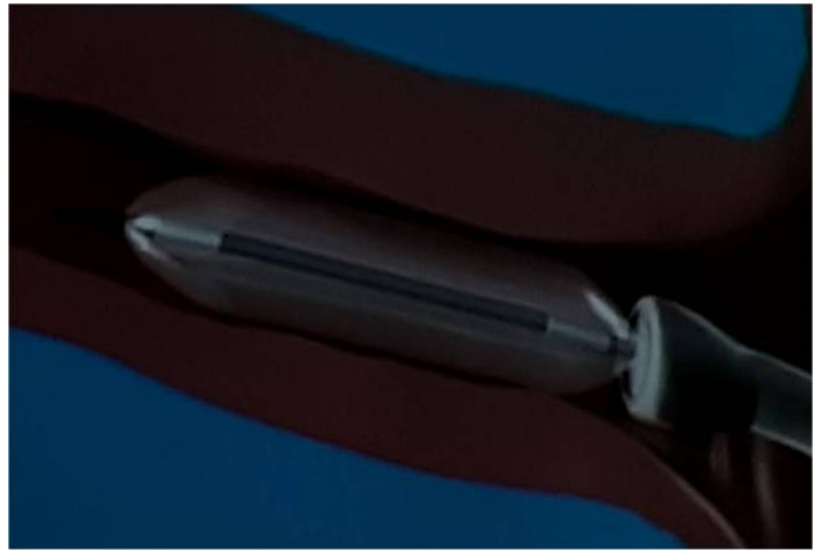

Figure 4: Widening of the cartilaginous part of the ET during balloon inflation.

\section{DRAWBACKS OF THE TECHNIQUE}

There is no clinical data available for learning curve of intranasal endoscopic balloon dilation of eustachian tube. One study documented 24 balloon dilatations of ET in cadavers suggested easier, shorter and mean operative time of $284 \mathrm{~s} .{ }^{30}$ The longest duration for placement and dilatation of the balloon catheter is an average of 100 and $142 \mathrm{~s}$ respectively. These steps may likely fail and need revision dilation and placement of balloon catheter in the ET lumen. In case of procedure done under local anesthesia at outpatient department, require application topical anesthesia to the lumen of ET via a catheter. Study documented that refinement of this procedure is required for allowing duration of dilatation pressure effect in the lumen to be well tolerated. ${ }^{31,32}$ There is another concern for endoscopic balloon dilation of the ET is its use in the pediatric age group where middle ear diseases are more prevalent. ${ }^{33}$ This is because of shorter, wide and horizontal eustachian tube with length is less than half the size of an adult ET. ${ }^{19}$ (A2) There are two retrospective case series which documented ET balloon dilation in 33 pediatric patients with age 4 to 14 years, and in 66 pediatric patients with age 4 to 14 years showed no complications and resulted in improvement of middle ear symptoms. ${ }^{34,35}$

\section{POST-OPERATIVE COMPLICATIONS}

Transnasal endoscopic balloon dilation is a low risk surgical procedure where post-surgery pain is minimal and often patients can return to normal activities after a day of surgery. There are certain theoretical complications recorded in the literature such as internal carotid artery rupture, permanent conductive hearing loss, damage to the ET, scarring, stenosis, middle ear infections and otalgia. ${ }^{36}$ ET dilatation is often avoided in pediatric age group. One study documented minor epistaxis or nasal bleeding in ET balloon dilatation. ${ }^{37}$ There are serious complications like subcutaneous emphysema in the neck reported in another study. ${ }^{38}$ Acute otitis media was also reported as complication of balloon 
dilatation of ET, for which post-operative prophylactic antibiotics are advised. ${ }^{39}$ The proximity of the internal carotid artery has clinical importance as often require to prevent catastrophic injuries and death which has been anecdotally documented in the past during injection procedures in patulous ET. ${ }^{40}$ There are no cases reported for complications of carotid artery injury or patulous ET. But there is theoretical risk for injury to a dehiscent carotid artery which runs adjacent to the bony part of the ET. Computed tomography (CT) scan of the petrous temporal bone is required as part of the pre-operative investigations. One study conducted a retrospective analysis of petrous temporal bone CT scan those underwent ET dilatation where authors found 24 balloon dilatations were done in 17 patients with carotid artery canal dehiscence without any complications or any difficulties. Long-term studies are required to evaluate the lasting benefits and safety of transnasal balloon dilation of the ET.

\section{CONCLUSION}

Transnasal endoscopy guided balloon dilatation of eustachian tube is a novel technique to perform minimal invasive eustachian tube dilation for improvement of the ET dysfunction. The objective of the balloon eustachian tuboplasty is to widen the cartilaginous portion of the eustachian tube and enhances the physiological functions with minimal or no complications. This minimally invasive procedure is now a proved to be feasible and safe in the treatment of the ET dysfunction. This is a low risk surgical technique where postsurgical pain is minimal, and patients can return to normal activities following a day of surgery. Transnasal endoscopic balloon dilation of ET proves to be long term solution for chronic ear diseases.

\section{Funding: No funding sources \\ Conflict of interest: None declared \\ Ethical approval: Not required}

\section{REFERENCES}

1. Browning GG, Gatehouse S. The prevalence of middle ear disease in the adult British population. Clinical Otolaryngol Allied Sci. 1992;17(4):317-21.

2. Sudhoff H, Bücker R, Groll C, Shagdarsuren S, Dazert S, Schreiber S. Tracing of gastric reflux into the middle ear in a Mongolian gerbil model. Otol Neurotol. 2007;28(1):124-8.

3. Swain SK, Samal R, Pani SK. Effect of smoking on outcome of tympanoplasty. Ind $\mathrm{J}$ Otol. 2011;17(3):120.

4. Pahnke J. Morphology, function, and clinic of the Eustachian tube. Laryngo-Rhino-Otologie. 2000;79:1-21.

5. McCoul ED, Lucente FE, Anand VK. Evolution of Eustachian tube surgery. Laryngoscope. 2011;121(3):661-6.
6. Poe DS, Grimmer JF, Metson R. Laser eustachian tuboplasty: two-year results. Laryngoscope. 2007;117(2):231-7.

7. Metson R, Pletcher SD, Poe DS. Microdebrider eustachian tuboplasty: a preliminary report. Otolaryngol Head Neck Surg. 2007;136(3):422-7.

8. Yamashita K. Pneumatic endoscopy of the Eustachian tube. Endo. 1983;15(04):257-9.

9. Hopf J, Linnarz M, Gundlach P, Schäfer E, Leege $\mathrm{N}$, Scherer H, et al. Microendoscopy of the Eustachian tube and the middle ear. Indications and clinical application. Laryngo-rhino-otologie. 1991;70(8):391-4.

10. Yamashita K. Endoscopy of the eustachian tube. Adv Otorhinolaryngol. 1987;37:53-9.

11. Ockermann T, Reineke U, Upile T, Ebmeyer J, Sudhoff HH. Balloon dilatation eustachian tuboplasty: a clinical study. Laryngo. 2010;120:1411-6.

12. Ockermann T, Reineke U, Upile T, Ebmeyer J, Sudhoff HH. Balloon dilation eustachian tuboplasty: a feasibility study. Otol Neurotol. 2010;31(7):11003.

13. Pau HW. Eustachian tube and middle ear mechanics. HNO. 2011;59(10):953-63.

14. Adil E, Poe D. What is the full range of medical and surgical treatments available for patients with Eustachian tube dysfunction? Curr Opinion Otolaryngol Head Neck Surg. 2014;22(1):8-15.

15. Llewellyn A, Norman G, Harden M, Coatesworth A, Kimberling D, Schilder A, McDaid C. Interventions for adult Eustachian tube dysfunction: a systematic review. Health Technol Assess (Rockv). 2014;18:1-180.

16. Metson R, Pletcher SD, Poe DS. Microdebrider eustachian tuboplasty: a preliminary report. Otolaryngol Head Neck Surg. 2007;136(3):422-7.

17. Smith ME, Tysome JR. Tests of Eustachian tube function: a review. Clini Otolaryngol. 2015;40(4):300-11.

18. Silvola J, kiveaks I, Poe D . Balloon dilation of the cartilaginous Eustachian tube. Otolaryngol Head Neck Surg. 2011;144(4):563-69.

19. Cummings CW, Haughey BH, Thomas JR. Cummings Otolaryngology: Head and Neck Surgery. 4th ed. Philadelphia: Elsevier Mosby, 2005: 321 .

20. Schröder S, Lehmann M, Ebmeyer J, Upile T, Sudhoff H. Balloon Eustachian tuboplasty: a retrospective cohort study. Clini Otolaryngol. 2015;40(6):629-38.

21. Poe DS, Abou-Halawa A, Abdel-Razek O. Analysis of the dysfunctional eustachian tube by video endoscopy. Otol Neurotol. 2001;22(5):590-5.

22. Kivekäs I, Chao WC, Faquin W, Hollowell M, Silvola J, Rasooly T, et al. Histopathology of balloon-dilation Eustachian tuboplasty. Laryngo. 2015;125(2):436-41.

23. Sudhoff H, Ockermann T, Mikolajczyk R, Ebmeyer J, Korbmacher D, Garten D, et al. Clinical and 
experimental considerations for evaluation of Eustachian tube physiology. HNO. 2009;57:428-35.

24. Adil E, Poe D. What is the full range of medical and surgical treatments available for patients with Eustachian tube dysfunction?. Curr Opinion Otolaryngol Head Neck Surg. 2014;22(1):8-15.

25. Norman G, Llewellyn A, Harden M, Coatesworth A, Kimberling D, Schilder A, et al. Systematic review of the limited evidence base for treatments of E ustachian tube dysfunction: a health technology assessment. Clini Otolaryngol. 2014;39(1):6-21.

26. Tisch M, Maier S, Maier H. Eustachian tube dilation using the Bielefeld balloon catheter: clinical experience with 320 interventions. HNO. 2013;61(6):483-7.

27. Schröder S, Reineke U, Lehmann M, Ebmeyer J, Sudhoff H. Chronic obstructive eustachian tube dysfunction in adults: long-term results of balloon eustachian tuboplasty. HNO. 2013;61(2):142-51.

28. Rietz A. How effective is balloon dilation for treatment of Eustachian tube dysfunction in adults?. Evidence-Based Prac. 2019;22(5):18-9.

29. Huisman JM, Verdam FJ, Stegeman I, de Ru JA. Treatment of Eustachian tube dysfunction with balloon dilation: A systematic review. Laryngo. 2018;128(1):237-47.

30. McCoul ED, Singh A, Anand VK, Tabaee A. Balloon dilation of the eustachian tube in a cadaver model: technical considerations, learning curve, and potential barriers. Laryngoscope. 2012;122(4):71823.

31. Anand V, Poe D, Dean M, Roberts W, Stolovitzky $\mathrm{P}$, Hoffmann $\mathrm{K}$, et al. Balloon dilation of the eustachian tube: 12-month follow-up of the randomized controlled trial treatment group. Otolaryngol Head Neck Surg. 2019;160(4):687-94.

32. Catalano PJ, Jonnalagadda S, Vivian MY. Balloon catheter dilatation of Eustachian tube: a preliminary study. Otol Neurotol. 2012;33(9):1549-52.
33. Jenckel F, Kappo N, Gliese A, Loewenthal M, Lorincz BB, Knecht R et al. Endonasal dilatation of the eustachian tube (EET) in children: feasibility and the role of tubomanometry (Esteve) in outcomes measurement. Eur Arch Otorhinolaryngol. 2015;272:3677-83.

34. Dalchow CV, Loewenthal M, Kappo N, Jenckel F, Loerincz BB, Knecht R. First results of Endonasal dilatation of the Eustachian tube (EET) in patients with chronic obstructive tube dysfunction. European Archives of Oto-Rhino-Laryngology. 2016;273(3):607-13.

35. Maier S, Tisch M, Maier H. Balloon dilation of the Eustachian tube in pediatric chronic obstructive Eustachian tube dysfunction patients. HNO. 2015;63(10):686-8.

36. Ockermann T, Reineke U, Upile T, Ebmeyer J, Sudhoff HH. Balloon dilatation eustachian tuboplasty: a clinical study. Laryngo. 2010;120(7):1411-6.

37. Schröder S, Reineke U, Lehmann M, Ebmeyer J, Sudhoff H. Chronic obstructive eustachian tube dysfunction in adults: long-term results of balloon eustachian tuboplasty. HNO. 2013;61(2):142-51.

38. Wanscher JH, Svane-Knudsen V. Promising results after balloon dilatation of the Eustachian tube for obstructive dysfunction. Dan Med J. 2014;61(4):A4818.

39. Busby DR, Slemmons DH, Miller TF. Fatal epistaxis via carotid aneurysm and eustachian tube. Archi Otolaryngol. 1968;87(3):295-8.

40. Abdel-Aziz T, Schroder S, Lehmann M, Gehl HB, Ebmeyer J, Sudhoff H. Computed tomography before balloon eustachian tuboplasty-a true necessity? Otol Neurotol. 2014;35:635-8.

Cite this article as: Swain SK, Das A, Acharya S, Mohanty JN. Transnasal endoscopic eustachian tube balloon dilation: a review. Int J Otorhinolaryngol Head Neck Surg 2020;6:207-12. 